\title{
RESPONSES OF SOIL FACTORS TO NUTRIENT INPUTS UNDER DIFFERENT FARMLAND USES
}

\author{
MA, X. ${ }^{1,2,3}-\mathrm{WU}, \mathrm{H} .{ }^{3}-\mathrm{CHEN}, \mathrm{H} .{ }^{4}-\mathrm{SUN}, \mathrm{R} .{ }^{5}-$ YANG, X. ${ }^{3}-\mathrm{QIAO}, \mathrm{W} .{ }^{1}-\mathrm{FANG}$ B.$^{1^{*}}$ \\ ${ }^{I}$ School of Geography Science, Nanjing Normal University, Nanjing 210023, China \\ ${ }^{2}$ Institute of Geographical Sciences, Henan Academy of Sciences \\ Henan Province, Zhengzhou 450052, China \\ ${ }^{3}$ Huzhou City Environmental Monitoring Center Station, Huzhou 313000, China \\ ${ }^{4}$ Education in Qingfeng County, Puyang City, Henan Province, Puyang 457300, China \\ ${ }^{5}$ Puyang City Environmental Monitoring Center Station, Puyang 457343, China \\ *Corresponding author \\ e-mail:wenyanfag731@163.com
}

(Received $12^{\text {th }}$ Oct 2018; accepted $19^{\text {th }}$ Nov 2018)

\begin{abstract}
To understand the responses of changes of soil factors to nutrient inputs under different farmland uses, we analysed soil test data from different crop land uses before and after harvest in combination with the farmers' survey over the cultivation years in Pujiang County, Zhejiang Province, China. The results showed that the inputs of the crop nutrients and the levels of soil nutrients were significantly correlated on the regional scale. Farmers' fertilisation habits resulted in an excess of phosphorous and potassium in the soil, potentially leading to environmental pollution. The excessive investment of nitrogen and phosphate may have decreased the farmland soil's $\mathrm{pH}$ value. For vegetable crops, no significant correlation between the crop nutrient and the levels of soil nutrients was found.This might be due to the randomness of nutrient inputs mainly driven by economic interests. We suggest that soil tests be carried out to help improve nutrient management in Pujiang County, especially for non-cereal and oil crops.
\end{abstract}

Keywords: farmland use, soil fertility factor, nutrient inputs, soil factor response, Pujiang County, China

\section{Introduction}

Rapid urbanisation and industrialisation in China have increased the need for cultivated land protection (Cai, 2000). In recent years, the quantity of cultivated land in China has decreased while the quality of the land has degraded (Zhang and Wang, 2000; Gao et al., 2000; Chen et al., 2012; Cai et al., 2004a), characterised by soil erosion, pollution, and a decline in soil fertility. In many areas, excessive nutrient input, such as chemical fertilisers, has not only depleted resources but also caused environmental pollution and negatively affected farmland soil quality (Kou et al., 2004; Gao et al., 2009; Domanski et al., 2001). Zhang analysed the economics of crop fertilisation in Shandong province and concluded that the economic benefit was disconnected from resource efficiency in current crop production (Zhang and Ma, 2000; Liang et al., 2000; Benhl et al., 1991). After investigating Dongfeng County's fertiliser input, output, and economic benefit for a few years, Yu pointed out that the policy of diminishing returns of fertiliser did not change people's minds. When the fertiliser input exceeded a certain limit, both the benefit of the fertiliserand the output of crop will be reduced ( $\mathrm{Yu}$ et al., 2004; Bruland and Richardson, 2005). Using a small watershed as a unit, Guo analysed 
the fertiliser input, the accumulation of soil $\mathrm{NO}_{3}-\mathrm{N}$, and its influence on the gully region of the Loess Plateau. The results showed that the input of chemical fertiliser was an important support and guarantee factor for the adjustment of land use structure in the basin. Fertilizers have increased the area planted with food crops, and the area of nonfood land has begun to decrease and that the land use structure had further stretched the fertiliser input (Guo et al., 2003a; Guo et al., 2003b; Li et al., 2008; Zhao et al., 2009; Cai et al., 2004b; Lu, 1998). The research on the relationship between the grain yield of wheat and maize and the fertiliser input in the Huanghuaihai plain showed a serious imbalance in the application of chemical fertiliser for current crop production; the application of chemical fertiliser was no longer the main measure for increasing the output. Reasonable coordination and improvement of the fertiliser utilisation rate was an important measure of energy efficiency (Wu et al., 2003; Lu et al., 2004; Wang et al., 2004). All of these studies have revealed low efficiency in utilising fertilisers for production in China. However, there is an explanation for the relationship between the spatial effects of nutrient inputs and the soil factor in the planting period, according to the test data. On the basis of the soil test data from different types of land usefor crop planting in combination with the farmers' survey data for many years, this study presents the nutrient input effects on the soil factors of different types of land usein the planting period. The results can be useful for the rational investment of different nutrients and the proper adjustment of planting structures in different regions.

\section{Materials and methods}

\section{Research area}

Zhejiang Province is located on the southeast coast of China,and Pujiang County is located in the middle of Zhejiang Province (east longitude $119^{\circ} 42^{\prime}-120^{\circ} 07^{\prime}$, north latitude $29^{\circ} 21^{\prime}-29^{\circ} 41^{\prime}$ ), on the rim of the Jinqu Basin. It is the source of the Puyang and Huyuan Rivers. The whole land area is $907.6637 \mathrm{~km}^{2}$ (east to west $39.25 \mathrm{~km}$ wide, north to south $36.5 \mathrm{~km}$ long). The northwest mountainous area and Pujiang Basin are two types of landscapes in Pujing County. The northwestern mountainous area belongs to a hilly ground landform that is mainly lofty and is composed of low hills. Pujiang Basin belongs to the Jinqu hilly basin landform, which is mainly flat farmland, downland, and low hills. The landforms in Pujiang County can be divided into three classes based on height and agricultural use: flatland (elevation lower than $150 \mathrm{~m}$ ), midlevel district (elevation between $150 \mathrm{~m}$ and $500 \mathrm{~m}$ ), and mid-low mountain area (elevation higher than $500 \mathrm{~m}$ ) (Figure 1). The landscape accords with the seven mountains, two rivers, and one field terrain featured in eastern China. Pujiang County is a subtropical zone with a monsoon climate, distinct seasons, a moderate temperature, sufficient light, and abundant rainfall and natural resources.

In the agricultural land adjacent to the Puyang and Huyuan Rivers, three microclimate belts are formed: the Pujiang Basin, with a small warm and rainy area (area I); the Huyuan River Valley, with a mild and rainy area (area II); and a low, mountains, cool and rainy area (area III; Figure 1). The climatic characteristics are shown in Table 1 .

The regional economic development level in Pujiang County is slightly higher than the national average. Rapid industrial expansion added unprecedented challenges to cultivated land protection. The optimisation of regional resources is becoming an imminent problem. 


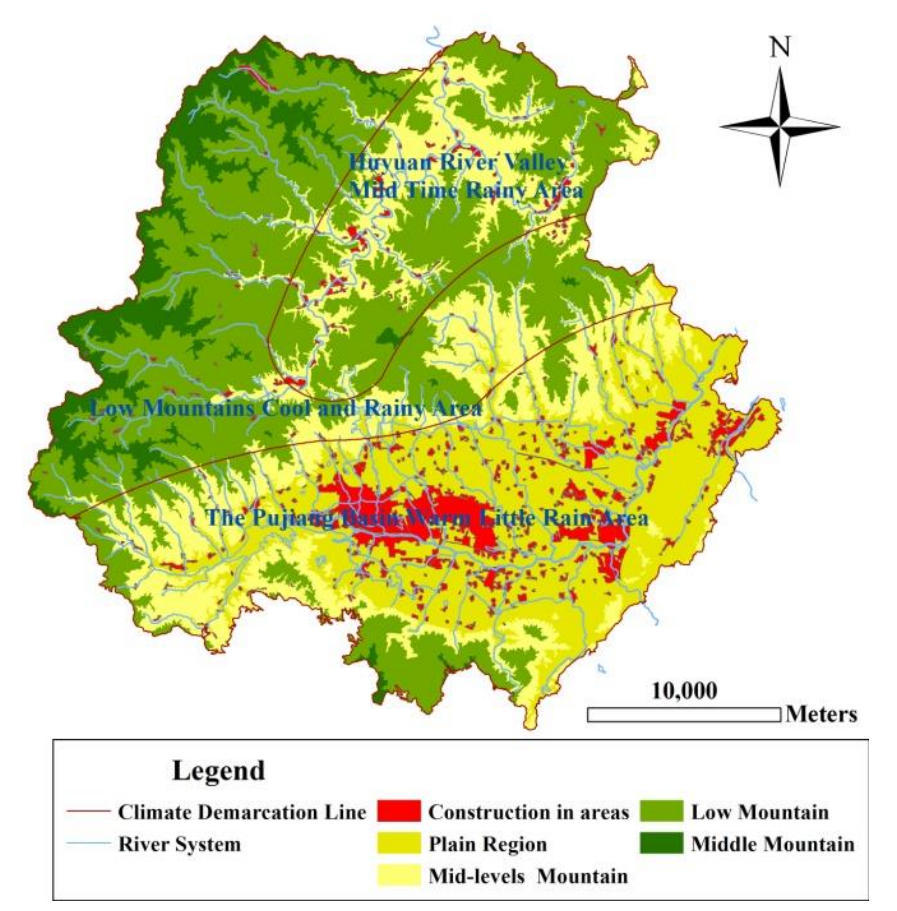

Figure 1. Geographical features of Pujiang County

Table 1. Main soil characteristics of the agricultural climate in Pujiang

\begin{tabular}{c|c|c|c|c|c}
\hline Area & $\begin{array}{c}\text { Elevation } \\
(\mathbf{m})\end{array}$ & $\begin{array}{c}\text { Average } \\
\text { temperature } \\
\left({ }^{\circ} \mathbf{C}\right)\end{array}$ & $\begin{array}{c}\text { Annual rainfall } \\
(\mathbf{m m})\end{array}$ & $\begin{array}{c}>=\mathbf{1 0}{ }^{\circ} \mathbf{C} \text { accumulated } \\
\text { temperature }\end{array}$ & Soil \\
\hline I & $70-300$ & $16-17$ & $1250-1400$ & $4900-5200$ & $\begin{array}{c}\text { Alluvial plain: loamy, } \\
\text { paddy soil }\end{array}$ \\
\hline II & $28-500$ & $15-16$ & $1400-1500$ & $4600-4900$ & $\begin{array}{c}\text { Colluvial valley: clayey, } \\
\text { paddy soil }\end{array}$ \\
\hline III & $500-1200$ & $13.5-15$ & $1500-1577$ & $3900-4600$ & Hillock: clayey, red soil \\
\hline
\end{tabular}

\section{Study methods}

\section{Household survey}

\section{Investigation method}

We use a combination of stratified sampling and PPS sampling to chose 107 representative farmers for interviews. The farmers were selected using the method of point, line, and surface. The surface covered a wide range of area. We divided the county into three parts (plain district, mountain district, and low mountain district), and we gave consideration to each village or town in the county. In the meantime, we also considered crop varieties, planting areas, climate differences, typical products, and major industries to balance all these factors. We used a highway as the first line, a pond or ditch as the second line, and a mountain road as the third line. For the point, we considered three classes of crop production levels in addition to the crop variations. The distribution of the survey point is shown in Figure 2. The investigational interviews were conducted by professionals of local agricultural technology in the villages or towns, along with university professors and graduate students. These interviewers used a unified, standard door-to-door survey to interview selected crop growers. 


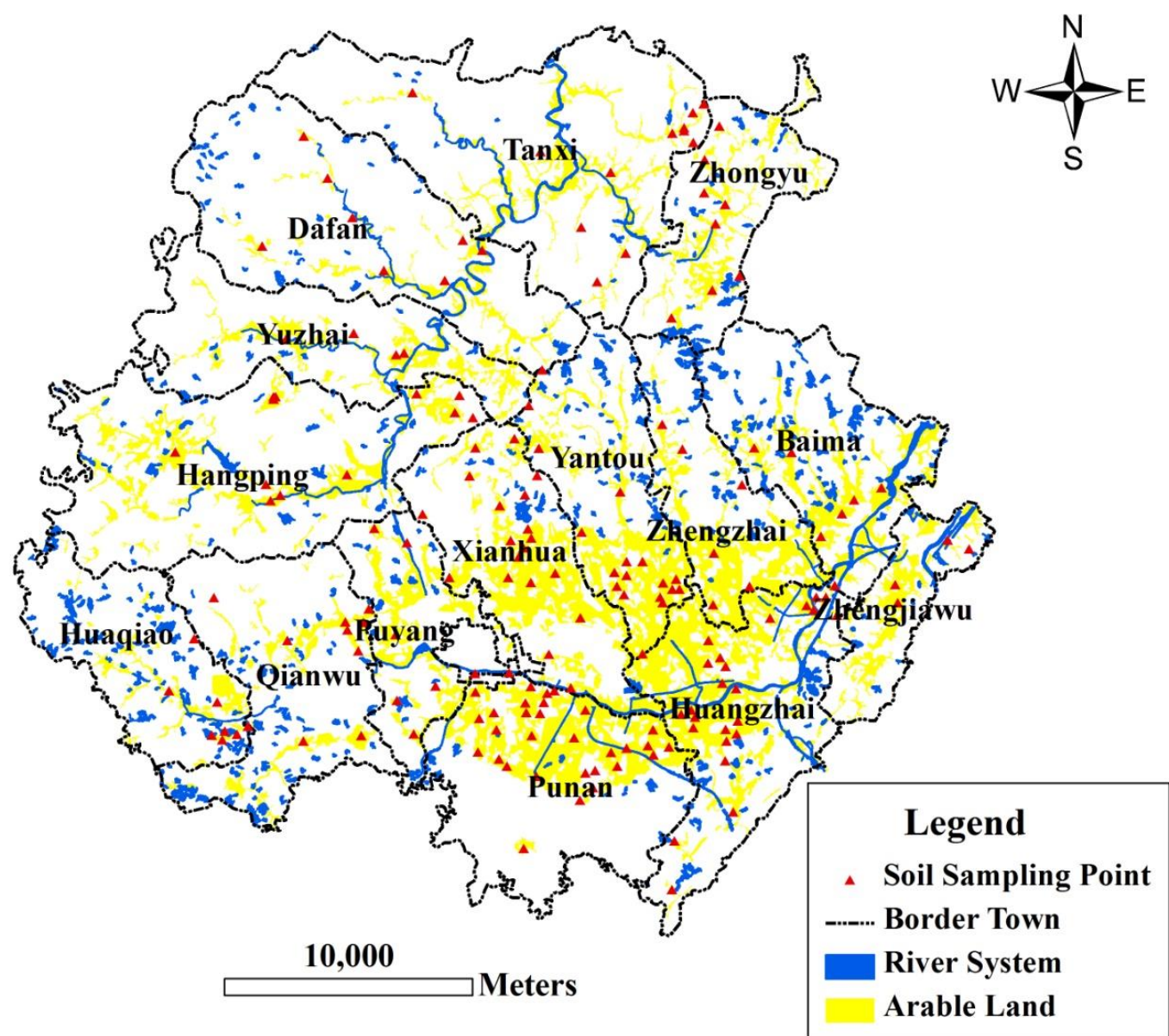

Figure 2. Distribution of sampling points

\section{Investigation content}

We designed a detailed questionnaire before the investigation. The main contents included: 1) The status of the use of land, existing problems in agricultural production, crop species, crop yields, the price of agricultural products, the situation of crop growth, and the disasters that occurred in the last 5 years. These data serve to evaluate different benefits of the use of land. 2) Basic information on the farming field, such as terrain conditions, geographical location, and soil properties. These data set the fundamental factors for the spatial analysis of the patterns of land use. 3) Crop management techniques: land consolidation, machine use, inputs and practice methods for all kinds of fertilisers and inputs, the use of various pesticides, and the production and efficiency of agriculture. These data can be used to analyse the relationship between soil nutrients, spatial change, and land usage.

\section{Sampling test and analysis}

The sampling point layout

The cultivated land in Pujiang Basin was concentrated in the northwest, along both sides of HuYuanjiang. On the $0 \sim 20 \mathrm{~cm}$ soil layer of each cultivated land sampling unit, the appropriate layout method is determined according to the shape and size of the unit, 
that is, the rectangular block adopts the "S" method, and the approximate square block adopts the "X" method or the checkerboard layout. For areas with complex soil types and topographical conditions, the sampling density is appropriately increased for the dominant crop or cash crop planting area.

The location and altitude of the sample space were determined by a differential GPS instrument, and the surrounding landscape information, farming system and production capacity were investigated and recorded. After thoroughly mixing the collected soils, a $1.5 \mathrm{~kg}$ soil sample bag was taken by the quarter method for analysis. We chose a total of 173 sampling points from 107 household fields using a topographic map and a present map of land use in combination with on-the-spot investigation. There was a total of 57 pieces of rice (including rapeseed), 33 pieces of grapes, 32 pieces of vegetables, 21 pieces of peach plum and other pieces totalling 30. Every point layout is shown in Figure 2.

\section{Soil sampling method}

(1) Sampling time: The first sampling time was before sowing (March 3-12, 2018, a total of 10 days), and the second time for sampling was after harvest and before fertilisation (from November 25 to December 4, 2018, a total of 10 days). The sampling time was integrated with the features of seasonal characteristics and farming activities in the region. The same sampling plots were used for the two sampling periods.

(2) Sampling site and depth: The sampling depth was determined according to the topsoil thickness, usually between 0 and $20 \mathrm{~cm}$.

(3) Sampling method and quantity: We adopted the method of multi-point, mixedsoil sampling, and each mixed agricultural soil sample consisted of 20 sites. First, we tried to make the depth and weight of each sampling point as uniform as possible.The upper and lower proportions of the soil samples were basically the same. We avoided using metal utensils and rubber products during the handling and storage process, because it will pollute the sample. The weight of each composite sample was about $1 \mathrm{~kg}$.

\section{Analysis and testing method}

The method of diffusion and absorption was summarised by $\mathrm{Lu}$, the $\mathrm{pH}$ value of the soil was determined by $\mathrm{pH}$ meter. The soil organic matter was determined by the weight acid method-concentrated sulfuric acid external heating method. The whole $\mathrm{N}$ was semi-micro-Kelvin method, and the whole $\mathrm{P}$ was $\mathrm{Na} \mathrm{OH}$ melting-molybdenum anticolorimetric method. Using $\mathrm{Na} \mathrm{OH}$ melt-flame photometry, the alkali solution $\mathrm{N}$ is alkali diffusion method, the effective $\mathrm{P}$ is $\mathrm{Na} \mathrm{HCO} 3$ extraction - molybdenum antimony colorimetric method, and the quick effect $\mathrm{K}$ is NH4OAc extraction - flame photometry. We tested and analysed the samples according to the analytical method in line with national standards (Lu, 2000; Liu and $\mathrm{Wu}$ ). We performed correlation analysis between geographical elements, and the correlation coefficient was determined between the calculation and test.

\section{Correlation analysis method}

Correlation analysis is used to reveal the intimate degree of interrelations between geographical elements by calculating and testing the correlation coefficient. 


\section{Calculation of correlation coefficient}

If we have a series of $\mathrm{n}$ measurements of $\mathrm{X}$ and $\mathrm{Y}$ written as $\mathrm{xi}$ and yi, where $\mathrm{i}=1,2$, $\ldots, \mathrm{n}$, then the correlation coefficient between them is defined as

$$
r_{x y}=\frac{\sum_{i=1}^{n}\left(x_{i}-\bar{x}\right)\left(y_{i}-\bar{y}\right)}{\sqrt{\sum_{i=1}^{n}\left(x_{i}-\bar{x}\right)^{2} \sum_{i=1}^{n}(y 1-\bar{y})^{2}}}
$$

whereError! Reference source not found. $\bar{x}$ and Error! Reference source not found. are the sample means of $\mathrm{X}$ and $\mathrm{Y}$ (i.e. $\left.\bar{X}=\frac{1}{n} \sum_{i=1}^{n} X_{i}, \bar{Y}=\frac{1}{n} \sum_{i=1}^{n} Y_{i}\right), r_{x y}$ is the correlation coefficient between $\mathrm{X}$ and $\mathrm{Y}$, which is a statistical indicator calculated to show their degree of correlation. Its value lies in the range $[-1,1]$, with a positive value indicating positive correlation and a negative value indicating negative correlation. The nearer the absolute value of $r_{x y}$ approximates to 1 , the closer $\mathrm{X}$ and $\mathrm{Y}$ are; the closer it approximates to 0 , the less correlated they are.

\section{Correlation coefficient test}

The correlation coefficient test checks the correlation coefficient against a threshold with a given confidence level. The formula is shown as the following: Error! Reference source not found. $p\left\{r \mid>r_{\alpha}\right\}=\alpha$ where $\alpha$ means different levels of confidence. If the absolute value of $\mathrm{r}$ is greater than the threshold $r_{\alpha}$ with the confidence level $\alpha, \mathrm{X}$ and $\mathrm{Y}$ are uncorrelated.

\section{The results of the study and analysis}

\section{Statistical analysis results}

Results of nutrient input for different crops nutrient inputs

By the means of statistics, calculation, empirical correction, and the abnormal value reject of $\mathrm{N}, \mathrm{P}$, and $\mathrm{K}$ investment in a county, getting the final results of the corresponding $\mathrm{N}, \mathrm{P}$, and $\mathrm{K}$ average amounts of different crops per hectare, the results are shown in Table 2.

\section{Crop distribution within the region}

The structure of the planting crop is normally determined by the traditional market, economics, and technical skills in the region. The survey results in Pujiang showed a stable crop structure. In the towns of Huangyan, Yantou, and Zhengzhai, the main crop is grapes, which occupies $18.53 \mathrm{~km}^{2}$. For the Qianwu village and Puyang Street, the main crops are vegetables, and these areas are mainly located on both sides of the Yangjiang River, which supplies plentiful water and has a short distance to the city. The acreage for these areas is $7.49 \mathrm{~km}^{2}$.

With a high altitude and great variation of temperature, Hang Ping town is the main production area for mountain vegetables. The planting area is $7.49 \mathrm{~km}^{2}$. For food crops, 
most families are self-sufficient, and the general area for food crops is about $6.67 \mathrm{~km}^{2}$, as shown in Figure 3.

Table 2. Mean inputs of $N, P$, and $K$ for different crops

\begin{tabular}{|c|c|c|c|c|c|c|c|c|c|c|c|}
\hline \multirow{2}{*}{ Nutrient } & \multicolumn{5}{|c|}{ Grain and oil crop (kg/ha) } & \multicolumn{5}{|c|}{ Grapes and other fruit (kg/ha) } & \multirow{2}{*}{$\begin{array}{c}\begin{array}{c}\text { Vegetables } \\
\text { (kg/ha) }\end{array} \\
\text { vegetables }\end{array}$} \\
\hline & rice & rapeseed & sorghum & corn & wheat & grape & watermelon & sugar & pear & $\begin{array}{l}\text { peach } \\
\text { plum }\end{array}$ & \\
\hline $\mathrm{N}$ & 200 & 100 & 45 & 145 & 210 & 430 & 387 & 290 & 350 & 130 & 450 \\
\hline $\mathrm{P}$ & 18 & 11 & 60 & 20 & 40 & 105 & 189 & 120 & 180 & 30 & 210 \\
\hline $\mathrm{k}$ & 60 & 20 & 25 & 65 & 25 & 200 & 178 & 125 & 154 & 35 & 160 \\
\hline
\end{tabular}

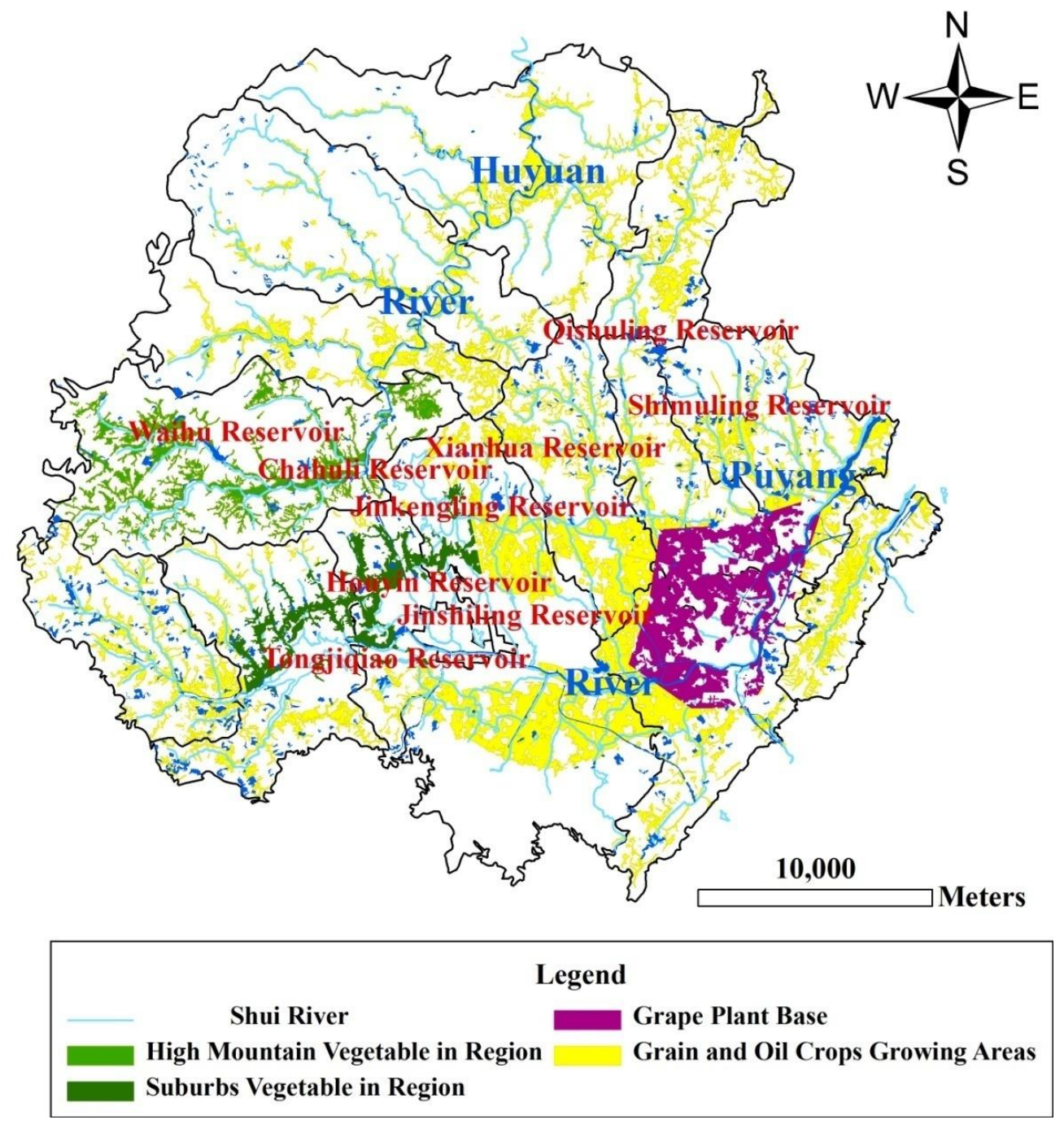

Figure 3. Crop planting areas

\section{The statistical results of soil factors}

The change of soil factors

We observed small variations (between $-6 \%$ and $6 \%$ ) in soil $\mathrm{pH}$ and organic matter 
content in different land uses. The fruit land had the highest variation in $\mathrm{pH}$, with a positive correlation with elevation. The $\mathrm{pH}$ of vegetable soils, however, was negatively related to elevation. The content of the alkali solution of nitrogen and rapidly available phosphorus and potassium in the soil varied greatly $(26.49 \% \sim 78 \%)$ between the two sampling time points, and the mean values of data collected during the second sampling were generally higher than those of the first sampling period (Figure 4).

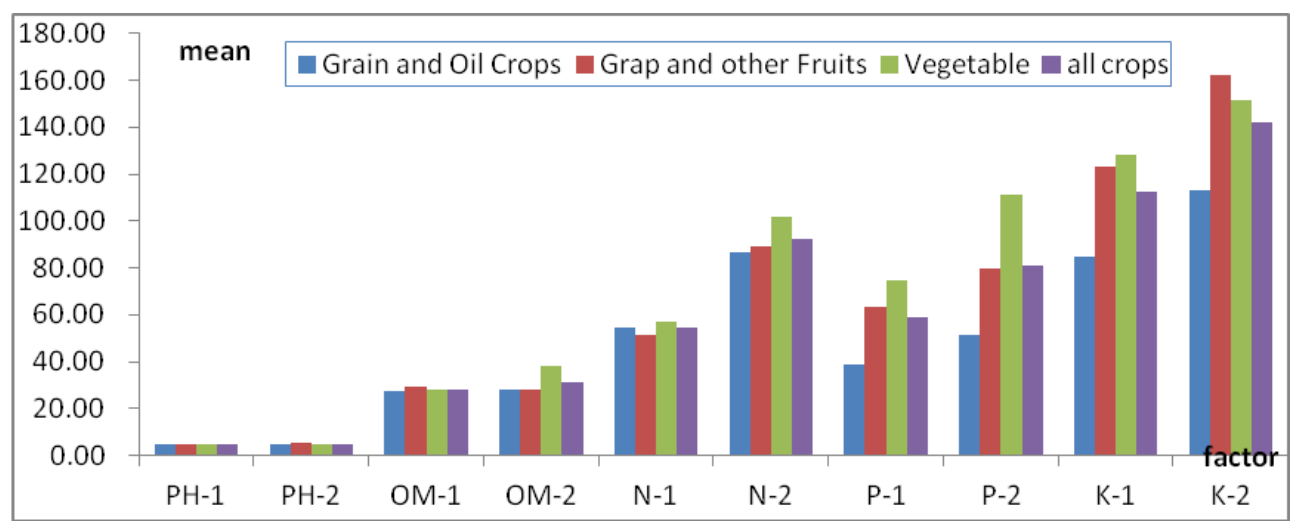

Figure 4. Values of $\mathrm{pH}$ and nutrient content in soil before and after different crop plantings (Note: The abscissa is a different soil element, ph-1 and ph-2 itself has no unit, OM-1 OM-2 N-1 $N-2 P-1 P-2 K-1 K-2$, the units was $\mathrm{g} / \mathrm{kg}$. The ordinate represents the amount of change in elements, the units is \%)

Nutrient inputs and other factors of crop production had little effect on soil $\mathrm{pH}$ and organic matter between the two sampling periods. This might be related to the physical and chemical properties of the soil $\mathrm{pH}$ and organic matter themselves. According to the survey, chemical fertiliser was the main nutrient input for vegetable production, and excessive nitrogen fertiliser input resulted in a diminishing $\mathrm{pH}$ value. However, although the nutrient input in areas of fruit production was greater than needed, the soil $\mathrm{pH}$ did not decrease, but increased slightly, probably because alkaline, organic fertiliser was the dominant type used in these areas. The $\mathrm{N}, \mathrm{P}$, and $\mathrm{K}$ inputs were mainly from chemical fertilisers, which could be rapidly released in the soil in a short time, resulting in a rapid increase of available nitrogen, phosphorus, and potassium. Combining this with the $\mathrm{P}, \mathrm{N}$, and $\mathrm{K}$ investments in different crops, we concluded that the greater the amount of nutrient input, the lower the nutrient utilisation efficiency.

\section{The change in soil factor coefficients of variation}

The variation coefficient of variation $(\mathrm{CV})$ reflects the variation degree of soil factors of different crops. Generally, $0.01 \leq \mathrm{CV} \leq 0.16$ is weak variability, $0.16<\mathrm{CV} \leq 0.50$ is moderate variability, and CV>0.50 is strong variability (López-Granados et al., 2002). For different crops, the $\mathrm{CV}$ of the soil $\mathrm{pH}$ at the two sampled time points was between 0.09 and 0.13 , indicating that the $\mathrm{pH}$ value was relatively stable with weak variability. External factors, such as land use types, and the variation of production factors had little effect on the $\mathrm{pH}$ value. The $\mathrm{CV}$ value of organic matter in the soil varied between 0.26 and 0.31 , which is in the moderate intensity range. The certain variation between the two sampling times showed the variations among farmers due to differences in geographical environment, planting structure, and soil organic matter content. 
According to the general rule of the change of soil organic matter, in the short term, the value should not appear with so much variation; the reasons for this phenomenon may be closely related to the growing areas' distances from the water source and the farmers' nutrient inputs and their type. Our results indicated that an area with a short distance to water and more $\mathrm{N}$ inputs had greater variation in the soil's organic matter content.

Because of an abundant water supply at an early stage, the soil with grapes had an obvious change in soil organic matter content, while the soil with other fruits required less water, which meant its organic matter content did not change as greatly as in the soil with grapes. Therefore, the long distance from the water supply and the greater dispersion of organic matter in the soil resulted in a greater variation in $\mathrm{CV}$ values. The $\mathrm{CV}$ values indicated that all the crops' soil had little change in alkali solution $\mathrm{N}$ before and after planting, but the average value of the soil's alkali-hydrolysable nitrogen increased after harvest. This increase was accompanied by a greater standard deviation, suggesting a greater variation in the soil's available nitrogen. This principle was apparently applicable to the soils with grains, oil crops, and vegetable crops. However, the $\mathrm{CV}$ values were reduced, implying that the two crop $\mathrm{N}$ inputs might have a certain convergence, which was also in line with the results of the survey. The CV values of grapes and other fruit crops increased after harvest, which might be related to the use of different fruit species and the differences in nutrient inputs. The CV values of the soil's available phosphorus were greater than any other soil factor before planting. This illustrated a close relationship between the amount of rapidly available phosphorus content and the inherent soil properties. After harvest, except for the CV values of vegetables (maybe due to a smaller average increase in available phosphorus than with the other crops), the $\mathrm{CV}$ values of all the other crops decreased, probably due to the value of the average is increasing. This also implied that the $\mathrm{P}$ input had a strong relationship with the traditional inertia. The CV values of potassium and phosphorus were similar, although not identical. The differences might cause increased differences in input. The average content of potassium increased, and the CV value also increased (Table 3).

Table 3. Soil pH and variation coefficients of soil nutrients

\begin{tabular}{c|cccccccccc}
\hline Crop type & PH -1 & PH -2 & $\begin{array}{c}\text { Organic } \\
\text { material-1 }\end{array}$ & $\begin{array}{c}\text { Organic } \\
\text { material-2 }\end{array}$ & $\begin{array}{c}\text { Available } \\
\text { nitrogen-1 }\end{array}$ & $\begin{array}{c}\text { Available } \\
\text { nitrogen-2 }\end{array}$ & $\begin{array}{c}\text { Rapidly } \\
\text { available } \\
\text { phosphorus-1 }\end{array}$ & $\begin{array}{c}\text { Rapidly } \\
\text { available } \\
\text { phosphorus-2 }\end{array} \begin{array}{c}\text { Rapidly } \\
\text { available } \\
\text { potassium-1 }\end{array} \begin{array}{c}\text { Rapidly } \\
\text { available } \\
\text { potassium-2 }\end{array}$ \\
\hline $\begin{array}{c}\text { Cereals and } \\
\text { oil crops }\end{array}$ & 0.11 & 0.10 & 0.26 & 0.22 & 0.19 & 0.16 & 0.87 & 0.73 & 0.45 \\
\hline $\begin{array}{c}\text { Grapes and } \\
\text { other fruits }\end{array}$ & 0.12 & 0.13 & 0.22 & 0.31 & 0.18 & 0.24 & 0.60 & 0.48 & 0.35 \\
\hline Vegetables & 0.10 & 0.09 & 0.19 & 0.24 & 0.18 & 0.16 & 0.45 & 0.49 & 0.47 \\
\hline All crops & 0.11 & 0.12 & 0.23 & 0.26 & 0.19 & 0.19 & 0.69 & 0.62 & 0.45 & 0.45 \\
\hline
\end{tabular}

\section{Correlation analysis and test of soil factor for different values}

To further explore the relationship between soil factors and nutrient inputs, we used the coefficient method of SPSS Pearson correlation and double sides of significant testing to calculate and test the correlations between $\mathrm{N}, \mathrm{P}$, and $\mathrm{K}$ input values and soil $\mathrm{pH}$ value, organic matter, alkali solution nitrogen, rapidly available phosphorus, and rapidly available potassium change value (Equation 1).

The results showed a strong negative correlation between D-YJ and D-pH, indicating that the value of reduced soil $\mathrm{pH}$ was beneficial to the formation of organic soil matter 
(Table 4). A significant positive correlation was found between D-YJ and D-JJN (p < 0.01 ), suggesting that the formation of organic matter was closely related to $\mathrm{N}$ value, while related data showed that the content of $\mathrm{P}$ and $\mathrm{K}$ had no correlation with the formation of organic matter. $\mathrm{N}$ input had a strong correlation with $\mathrm{P}$ and $\mathrm{K}$ inputs. However, the survey indicated that $\mathrm{P}$ and $\mathrm{K}$ inputs were not significant because compound fertilisers were widely applied. From the data, we found that the correlations of D-JJN and D-SXP reached an extremely significant level, but no significant correlation was found between D-JJN and D-SXK. This might be due to crop consistency, absorption capacity on $\mathrm{N}$ and $\mathrm{P}$, or that $\mathrm{N}$ and $\mathrm{P}$ leached into the soil or became volatile to the atmosphere. This also suggests that the ability of crop absorption and the atmosphere and soil's total loss of $\mathrm{N}$ and $\mathrm{P}$ are basically the same. For $\mathrm{N}$ and $\mathrm{K}$, however, crop absorption and loss were quite different.

Table 4. Soil factor index value and $N, P, K$ correlation analysis

\begin{tabular}{c|cccccccc}
\hline & D-PH & D-YJ & D-JJN & D-SXP & D-SXK & N input & P input & K input \\
\hline D-PH & 1 & $-.205^{* *}$ & -.097 & $-.168^{*}$ & .058 & $.199^{* *}$ & .069 & .145 \\
D-YJ & $-.205^{* *}$ & 1 & $.263^{* *}$ & .084 & -.083 & .032 & -.035 & -.092 \\
D-JJN & -.097 & $.263^{* *}$ & 1 & $.172^{*}$ & .080 & $.293^{* *}$ & $.174^{*}$ & .144 \\
D-SXP & $-.168^{*}$ & .084 & $.172^{*}$ & 1 & $.232^{* *}$ & .017 & $.446^{* *}$ & $.218^{* * *}$ \\
D-SXK & .058 & -.083 & .080 & $.232^{* *}$ & 1 & $.174^{*}$ & $.173^{*}$ & $.329^{* * *}$ \\
N input & $.199^{* *}$ & .032 & $.293^{* *}$ & .017 & $.174^{*}$ & 1 & $.508^{* *}$ & $.707^{* *}$ \\
P input & .069 & -.035 & $.174^{*}$ & $.446^{* *}$ & $.173^{*}$ & $.508^{* *}$ & 1 & $.771^{* * *}$ \\
K input & .145 & -.092 & .144 & $.218^{* *}$ & $.329^{* *}$ & $.707^{* *}$ & $.771^{* *}$ & 1 \\
\hline
\end{tabular}

Note: $(1) *$ indicates that through the bilateral significant test, the correlation coefficient is significant at the level of $\alpha=0.05$; $* *$ indicates that through the bilateral significant test, the correlation coefficient is significant at the level of $\alpha=0.01$, the same as below.

(2) D- represents the differences of the two sampling periods' test results of a factor; D-PH represents the difference in the soil's pH content value; YJ represents the soil's organic matter; JJN represents alkali solution N; SXP represents rapidly available phosphorus; SXK represents rapidly available potassium; "investment" represents the amount of a factor that farmers have used, such as "N investment" on behalf of farmers' input of pure $\mathrm{N}$; and $\mathrm{N}, \mathrm{P}$, and $\mathrm{K}$ respectively represent the pure $\mathrm{N}, \mathrm{P}$, and $\mathrm{K}$ inputs, the same as below

\section{Correlation analysis of grain and oil crop soil factor and investment factor difference}

For food crops, in the experiment period, N, P, and K inputs showed significant correlations, especially between $\mathrm{P}$ and $\mathrm{K}$ (Table 5), suggesting that the compound fertiliser application pattern had a strong performance in the grain crop.

Table 5. Correlation analysis between the changes in grain and oil crop soil factors and $N$, $P$, and $K$ inputs

\begin{tabular}{c|cccccccc}
\hline & D-PH & D-YJ & D-JJN & D-SXP & D-SXK & N input & P input & K input \\
\hline D-PH & 1 & -.150 & .042 & -.010 & .114 & -.201 & .112 & .155 \\
D-YJ & -.150 & 1 & .093 & .009 & -.016 & .200 & -.096 & -.159 \\
D-JJN & .042 & .093 & 1 & .229 & .005 & $.422^{* *}$ & $.302^{*}$ & $.241^{*}$ \\
D-SXP & -.010 & .009 & .229 & 1 & $.266^{*}$ & $.245^{*}$ & $.522^{* *}$ & $.325^{* *}$ \\
D-SXK & .114 & -.016 & .005 & $.266^{*}$ & 1 & .004 & .129 & $.405^{* *}$ \\
N input & -.201 & .200 & $.422^{* *}$ & $.245^{*}$ & .004 & 1 & $.382^{* *}$ & $.387^{* *}$ \\
\hline
\end{tabular}




\begin{tabular}{l|lllllllc}
\hline P input & .112 & -.096 & $.302^{*}$ & $.522^{* *}$ & .129 & $.382^{* *}$ & 1 & $.806^{* *}$ \\
K input & .155 & -.159 & $.241^{*}$ & $.325^{* *}$ & $.405^{* *}$ & $.387^{* *}$ & $.806^{* *}$ & 1 \\
\hline
\end{tabular}

Additionally, a strong correlation was shown between rapidly available phosphorus and rapidly available potassium, and no correlation was shown among the other factors (Table 5). This might be due to a strong correlation between $\mathrm{P}$ input and $\mathrm{K}$ input. In addition, the rate of utilisation of phosphorus and potassium for grain crops might be consistent, implying that the ability for grain crop in utilizing nitrogen might be entirely different. The data from the survey also reflected that the rate of fertilisation was quite different for various species of food crops from dry to paddy land; the $\mathrm{N}$ fertiliser rate was high in crops such as rice and low or even non-existentin crops such as legumes and sorghum. The survey results could be well validated by these data.

Correlation analysis of the impact of different soil factors and their inputs on grapes and other fruit crops

For the fruit crops, the differencesin soil factors resulted in different characteristics for food crops before and after harvest:

(1) A significant correlation was found between D-JJN and D-YJ (Table 6), demonstrating that the reduced $\mathrm{N}$ was closely related to the formation of organic matter, or excessive inputs of $\mathrm{N}$ had a stimulating effect on the formation of organic matter. This conclusion was consistent with the conclusion of related research (Liu et al., 1996; Hang et al., 2007).

Table 6. Correlation analysis between the changes of soil factors and N, P, and K inputs

\begin{tabular}{c|cccccccc}
\hline & D-PH & D-YJ & D-JJN & D-SXP & D-SXK & N input & P input & K input \\
\hline D-PH & 1 & $-.322^{* *}$ & -.195 & -.080 & -.106 & .007 & .089 & .106 \\
D-YJ & $-.322^{* *}$ & 1 & $.434^{* *}$ & .108 & -.066 & .204 & .095 & .046 \\
D-JJN & -.195 & $.434^{* *}$ & 1 & .143 & .140 & $.380^{* *}$ & .049 & .024 \\
D-SXP & -.080 & .108 & .143 & 1 & .218 & -.012 & $.552^{* *}$ & .171 \\
D-SXK & -.106 & -.066 & .140 & .218 & 1 & .133 & .193 & $.418^{* *}$ \\
N input & .007 & .204 & $.380^{* *}$ & -.012 & .133 & 1 & $.553^{* *}$ & $.694^{* *}$ \\
P input & .089 & .095 & .049 & $.552^{* *}$ & .193 & $.553^{* *}$ & 1 & $.724^{* *}$ \\
K input & .106 & .046 & .024 & .171 & $.418^{* *}$ & $.694^{* *}$ & $.724^{* *}$ & 1 \\
\hline
\end{tabular}

(2) There was also a significant negative correlation between D-YJ and D-pH (Table 6), suggesting that increased organic matter reduces soil's $\mathrm{pH}$ value. This further implies that too much input of $\mathrm{N}$ might lead to a decreased soil $\mathrm{pH}$. It can also explain why the values of soil $\mathrm{pH}$ in the tested 183 soil samples were all below 6 . This also accords with the analysis of the Techno GIN model (Fang and Wang, 2005, 2007; Fang et al., 2012). Excessive input of $\mathrm{N}$ was very common in Pujiang crop production, especially in the economic crop production.

(3) The correlations among the increments of soil nutrient factors are weak or even non-existent (see Table 6). This further explains that different crops' nutrient utilisation abilities are also different, and the interactions of crop types and the crop living environment have a decisive influence on crop nutrient usage.

(4) There was evident correlation between $\mathrm{N}$ input and the increase of soil alkali solution $\mathrm{N}$ content, and similar correlations existed between $\mathrm{P}$ input and the increase of 
the soil's rapidly available $\mathrm{P}$ content, and between $\mathrm{K}$ input and the increase of the soil's rapidly available $\mathrm{K}$ content.

\section{Correlation analysis of vegetable soil differences and input factors}

For vegetable crops, the relationships between the changes of soil factors and input factors were different from those described above before and after harvest. A strong correlation was not shown among input and the growth of soil exactable content, or soil variability, which was contrary to the general phenomenon: soil nutrient factors are closely related to nutrient inputs. However, according to the survey results, cropping patterns might have impacted this phenomenon because of large-scale cultivation and cultivation freedom. Except for the large-scale cultivation, which was relatively consistent, crop growers were free to cultivate the land in vastly different manners. For example, nitrogen input could be as high as $892 \mathrm{~kg} / \mathrm{ha}$ or as low as $75 \mathrm{~kg} / \mathrm{ha}$. The second difference in vegetable nutrient utilisation was the strong negative correlation between D-SXP and D-PH. In the combined survey results, the reasons for this phenomenon might be differences in $\mathrm{P}$ input. For example, vegetables, especially eggplant and peppers, need stem support, and therefore require more $\mathrm{P}$ input. Consequently, an excessive use of calcium phosphate monobasic reduced the soil $\mathrm{pH}$ value. $\mathrm{N}, \mathrm{P}$, and $\mathrm{K}$ changes in vegetables did not show any correlation (Table 7), suggesting a great variation in nutrient utilisation rates and capacities among different vegetable crops.

Table 7. Analysis of changes in vegetable soil factors and correlations with $N, P$, and $K$ inputs

\begin{tabular}{c|cccccccc}
\hline & D-PH & D-YJ & D-JN & D-SXP & D-K & N input & P input & K input \\
\hline D-PH & 1 & .228 & -.241 & $-.362^{*}$ & .113 & .141 & -.092 & -.152 \\
D-YJ & .228 & 1 & .095 & .174 & -.134 & -.032 & -.082 & -.184 \\
D-JN & -.241 & .095 & 1 & .112 & -.013 & .014 & .046 & .081 \\
D-SXP & $-.362^{*}$ & .174 & .112 & 1 & .286 & .002 & .168 & .092 \\
D-K & .113 & -.134 & -.013 & .286 & 1 & .134 & .175 & .142 \\
N input & .141 & -.032 & .014 & .002 & .134 & 1 & $.837^{* *}$ & $.823^{* *}$ \\
P input & -.092 & -.082 & .046 & .168 & .175 & $.837^{* *}$ & 1 & $.942^{* *}$ \\
K input & -.152 & -.184 & .081 & .092 & .142 & $.823^{* *}$ & $.942^{* *}$ & 1 \\
\hline
\end{tabular}

\section{Conclusions and discussion}

\section{Conclusion}

For most crops, the crop nutrient input and soil nutrient factor showed an extremely significant correlation in the regional range. Therefore, this relationship may be used to judge the rate of utilisation of adequate nutrients and to develop a quantified scheme to rationalise agricultural nutrient inputs and reduce environmental impact.

From the significant relationship between regional crop nutrient input and soil factors, we can conclude that compound fertiliser may be conducive to improving soil structure, but it leads to a large excess of phosphorus and potassium. Therefore, the acceleration of efficient soil testing engineering may be helpful to promote reasonable and targeted farmland fertilisation. 
An excessive investment of nitrogen and phosphate can lead to the reduction of farmland soil's $\mathrm{pH}$ value. This may be the direct reason that all the soils in Pujiang County farmland showed a $\mathrm{pH}$ value lower than 6 . Therefore, better management of nitrogen and phosphate fertilisation may significantly improve the quality of farmland soil. There is no significant correlation between the indicators of vegetable samples. The results of the survey reveal that the vegetable nutrient input is mainly driven by the economic interests of vegetable growers. This may have led to some random behaviours. We believe it is important to pay attention to the crop environment that may impact people's lives and daily diet.

Because of the limitations of real-world conditions, we did not repeat tests on all the sampling points. However, this does not diminish the importance of the study, which reveals problems in agricultural practice. More credible results may require additional investigation to provide more evidence and arguments. This will be the direction of our future efforts. However, whether soil testing and site-specific nutrient management can be used to shift the emphasis from food crops to economic crops is still debatable, because it may require a change of policy to create an incentive for crop growers.

\section{Deficiency}

We applied the correlation analysis and field research to study the response of soil factors to nutrient input under different cultivated land use patterns. It was concluded that compound fertilizer may be beneficial to improve soil structure. Excessive input of nitrogen and phosphorus will result in farmland soil $\mathrm{pH}$ reduce. The conclusions obtained are basically consistent with others, however, due to limited research time and other reasons, the paper still has some shortcomings to be further improved.

(1) The number of samples is not rich enough. Although it can meet the needs of the research, it may affect the accuracy of the correlation analysis. The subsequent research will increase the sample size appropriately.

(2) The paper mainly analyzes the structural factors such as soil properties and topography. The research on random factors such as farming and management is mainly through reading the literature and combining with field observations. Considering the validity of the survey data, in this paper, the application of the survey data is not sufficient, and there are still improvements to the mechanism revealing. In the follow-up study, attention will be paid to strengthening the quantitative analysis of the influence of structural and random factors.

\section{REFERENCES}

[1] Benhl, D. K., Biswas, C. R., Kalkat, J. S. (1991): Nitrate distribution and accumulation in an Uslochrept soil profile in a long term fertilizer experiment. - Fert. Res 28: 173-177.

[2] Bruland, G. L., Richardson, C. J. (2005): Spatial variability of soil properties in created, restored, and paired natural wetlands. - Soil Science Society of America Journal 69(1): 273-284. (In Chinese).

[3] Cai, Y. L. (2000): Problems of farmland conservation in the rapid growth of china's economy. - Resources Science 22(3): 24-28. (In Chinese).

[4] Cai, X. B., Zhang, Y. Q., Qian, C. (2004a): Effects of different fertilizing manners on the fertility characteristics of the degraded soil in central Tibet. - Acta Ecologica Sinica 24(1): 75-83. (In Chinese). 
[5] Cai, X. B., Qian, C., Peng, Y. L. (2004b): Fertility and restoration of degraded soil in central tibet. - Acta Pedologica Sinica 04: 603-611. (In Chinese).

[6] Chen, C., Lq, Y., Liu, J. F. (2012): Analysis and Control Measures of the Environmental Impact by Heavy Fertilizer Use. - South-to-North Water Transfers and Water Science \& Technology 10(A01): 102-104. (In Chinese).

[7] Domanski, G., Kuzyakov, Y., Siniakina, S. V., Stahr, K. (2001): Carbon flows in the rhizosphere of ryegrass (Lolium perenne). - Plant Nutr Soil Sci. 164: 381-387.

[8] Fang, B., Wang G. (2005): Analysis of cropnutrition limiting factors by TechnoGIN in Pujiang County of Zhejiang Province. - Journal of Zhejiang University (Agric.\& Life Sci.) 31(4): 417-522. (In Chinese).

[9] Fang, B., Wang G. (2007): Research on harmonious growth of eco-economy and agricultural N input. - Acta Ecologica Sinica 27(1): 214-219. (In Chinese).

[10] Fang, B., Wu, J. F., Ni, S. X. (2012): Correlation analysis of spatial variability of Soil available nitrogen and household nitrogen inputs at Pujiang County. - Acta Ecologica Sinica 32(20): 6489-6500. (In Chinese).

[11] Gao, X. Z., Ma, W. Q., Cui, Y. (2000): Changes of soil nutrient contents and input of nutrients in arable of China. - Plant Nutrition and Fertilizer Science 6(4): 363-369. (In Chinese).

[12] Gao, H. Y., Guo, S. L., Liu, W. Z. (2009): Soil respiration and carbon fractions in winter wheat cropping system under fertilization practices in arid-highland of the Loess Plateau. - Acta Ecologica Sinica 05: 2551-2559. (In Chinese).

[13] Guo, S. L., Hao, M. D., Dang, T. H. (2003a): N03--N accumulation and its affecting factors in small watershed in gully region of Loess Plateau. - Journal of Natural Resources 01: 37-43. (In Chinese).

[14] Guo, S. L., Zhou, Y. D., Zhang, W. J. (2003b): Effects of Long-term Application of Chemical Fertilizer on Food Production and Soil Quality Attributes. - Research of Soil and Water Conservation 01: 16-22. (In Chinese).

[15] Hang, G. X., Zhou, G. S., Xu, Z. Z. (2007): Spatial heterogeneity of soil respiration and contribution of root respiration in a maize (Zea mays L.) agricultural field. - Acta Ecologica Sinica 27(12): 5254-5251.

[16] Kou, C. L., Ju, X. T., Gao, Q. (2004): Effects of fertilization on soil quality in two different cropping systems. - Acta Ecologica Sinica 11: 2548-2555. (In Chinese).

[17] Li, H., Qiu, J. J., Wang, L. G. (2008): Characterization of farmland soil respiration and modeling analysis of contribution of root respiration. - Transactions of the CSAE 24(4): 14-20.

[18] Liang, G. Q., Lin, B., Lin, J. X., Rong, X. N. (2000): Effect of long-term fertilization on the forms of nitrogen in calcareous fluvo-aquic soil. - Plant Nutrition and Fertilizen Science 01: 3-10. (In Chinese).

[19] Liu, Y., Wu, H. (1997). The People's Republic national standards, soil qualityDetermination of lead, cadmium graphite furnace atomic absorption spectrophotometry. The People's Republic of national quality inspection and quarantine prison release. (In Chinese).

[20] Liu, X. L., Gao, Z., Liu, C. H. (1996): Effect of combined application of organic manure and fertilizers on crop yield and soil fertility in a located experiment. - Acta Pedologica Sinica 33(2): 138-147. (In Chinese).

[21] López-Granados, F., Jurado-Expósito, M., Atenciano, S., García-Ferrer, A., de la Orden, M. S., García-Torres, L. (2002): Spatial variability of agricultural soil parameters in southern Spain. - Plant and Soil 246: 97-105.

[22] Lu, R. K. (1998): Principle and Apply Fertilizer of Soil-Plant Nutrition. - Beijing: Chemical Industry Press 120-165. (In Chinese).

[23] Lu, Y. (2000): Soil agricultural chemical analysis method. - Beijing: Agricultural Scientech Press. (In Chinese). 
[24] Lu, A. X., Zhao, Y. L., Wang, J. H. (2004): Distribution characteristics of nitrogen and phosphorus in agricultural soil profiles under different landuse. - Acta Ecologica Sinica 04: 603-611. (In Chinese).

[25] Wang, H. Y., Zhou, J. M., Chen, X. Q., Du, C. W. (2004): Interaction of NPK fertilizers during their transformation in soils III. Transformations of monocaleium phosphate. Pedosphere 14(3): 379-385.

[26] Wu, L. F., Chen, F., Ouyang, Z. (2003): The relationship between grain output and fertilizer input in wheat-corn cropping area of the Huang-Huai-Hai plain. - Plant Nutrition and Fertilizing Science 9(3): 257-263. (In Chinese).

[27] Yu, Z. M., Li, P., Kang, S. D. (2004): An investigation of fertilizer for output and efficiency and scientific fertilization suggestion in Dong Feng County. - Journal of Jilin Agricultural Sciences 03: 62-67. (In Chinese).

[28] Zhang, F. S., Ma, W. Q. (2000): The Relationship between Fertilizer Input Level and Nutrient Use Efficiency. - Soil and Environmental Sciences 02: 154-157. (In Chinese).

[29] Zhang, T. L.,Wang, X. X. (2000): Development and orientation of research work on soil degradation. - Journal of Natural Resources 03: 280-284. (In Chinese).

[30] Zhao, Y. Y., Xie, Y. S., Hao, M. D. (2009): Effect of fertilization on fertility and nitrate accumulation of black loessial soil of dry land in Loess Plateau. - Plant Nutrition and Fertilizer Science 06: 1273-1279. (In Chinese). 